\title{
A Forensic Approach for Assessing Modes of Subsurface Petroleum Releases
}

\author{
John A. Anton', Gil Oudijk ${ }^{2}$ \\ ${ }^{1}$ Peak Environmental LLC, New Jersey, USA \\ ${ }^{2}$ Triassic Technology, Inc., New Jersey, USA \\ Email: John@peak-environmental.com,goudijk@triassictechnology.com
}

Received 18 January 2016; accepted 23 February 2016; published 26 February 2016

Copyright (C) 2016 by authors and Scientific Research Publishing Inc.

This work is licensed under the Creative Commons Attribution International License (CC BY). http://creativecommons.org/licenses/by/4.0/

\begin{abstract}
Chronic petroleum discharges resulting from underground storage tank (UST) system failures may continue for months or years, whereas catastrophic releases result from structural failures or overfills that occur over shorter time periods. A forensic analytical framework is useful for distinguishing between chronic and catastrophic releases and identifying responsible parties. However, the forensic program must account for the petroleum type because identifying release modes relies on understanding the chemical evolution of petroleum through time within the context of site conditions. Here we discuss key petroleum components that aid in reconstructing the release and identifying potential responsible parties when subsurface conditions are known.
\end{abstract}

\section{Keywords}

Age Dating, Biomarkers, Catastrophic and Chronic Environmental Discharges, Compound-Specific Stable-Isotope Ratios

\section{Introduction}

The mode of a petroleum release is the manner in which the discharge occurs, such as storage-tank leakage or overfills, and defining the type of petroleum release is often the key to securing monetary compensation through insurance coverage or litigation with responsible parties. A discharge can either be chronic, where it occurs over an extended period (months to years) or catastrophic, where it occurs rapidly (hours to weeks). Our experience shows that subsurface petroleum plumes with constant spatial chemical compositions are suggestive of catastrophic releases, whereas varying compositions imply chronic releases or releases of several different products of the same general type. Important to the analysis is identifying the petroleum type released. Petroleum or its dissolved-phase constituents may be encountered long after discharges occur. Identification is crucial to evaluate the release mode because petroleum chemistry changes with age and in response to ambient conditions. Chemi- 
cal variation is dependent on the composition of crude oil used by the refinery. Case studies are discussed where we employ these techniques to distinguish catastrophic and chronic releases.

Discerning petroleum types contributes to identifying responsible parties and designing remedial approaches. Data may be used in fate-and-transport models when remedial options are being considered. When poorlydocumented petroleum discharges occur, forensic-chemical analyses provide quantified data that provide a basis for identifying types of petroleum discharges. We define the term "forensic" in this paper as the use of science, technology or other information to reconstruct discharge events.

\section{Forensic-Chemical Framework}

\subsection{Sample Collection Considerations}

Separate-phase petroleum (light non-aqueous phase liquid (LNAPL)) is preferable for chemical fingerprinting [1]. The chemical signature of LNAPL is compared against known standards and the closest match identifies the fuel. Complications arise when a LNAPL contains multiple fuel types, similar fuels or weathered fuel. Fingerprinting can be supplemented with additional analyses, discussed later, to evaluate weathering.

Petroleum releases principally weather through evaporation, dissolution ("water washing") and biodegradation [2]. Weathering can be pronounced on an LNAPL's upper and lower interfaces because these surface areas may afford greater interaction with soil gas, bacteria, and water. Biodegradation within the LNAPL is limited by oxygen, water and nutrient availability [3]. Thick $(>15 \mathrm{~cm})$ LNAPLs generally experience reduced weathering compared to thinner layers. Additionally, petroleum LNAPLs, particularly middle distillates are nearly immiscible in water although dissolution can occur via turbulent mixing [4]. Potential exists for LNAPLs to remain chemically stable for $>20$ years.

Our practice is to collect at least two discrete LNAPL samples; one from the source area and a second from the plume's furthest edge to reconstruct degradation processes and estimate the release age. It is worth considering collecting discrete groundwater samples from below the LNAPL for analysis of dissolved-phase constituents as well because the resulting data provide information regarding kinetic and chemical interactions between the LNAPL and groundwater. Standard probes may be employed to document field conditions, such as $\mathrm{pH}$, conductivity and redox potential during sampling events and used with laboratory data to evaluate the petroleum-degradation history and thus release modes.

An indicator to estimate release timeframes is woody vegetation. Cores can be analyzed to identify when contaminants entered roots through correlations with annual growth rings [5]-[7]. However, few laboratories perform these tests and a cost-benefit analysis should be performed before developing costly studies.

\subsection{The Purpose of Laboratory Analyses}

The conventional semi-quantitative approach to identify unknown LNAPLs is to determine its chemical spectrum and boiling-point range of its constituents and compare these data to standards to determine a match. When the LNAPL is identified, deviations between the spectral peaks and standards can yield information on weathering and refinery processes. These data are significant because it constrains how quantitative data can be interpreted. Quantitative data, that indicate chronic or catastrophic releases, will be discussed in following sections.

\subsection{Investigating Diesel Fuel/Heating-Oil Releases: Fingerprinting and Age Dating}

In North America, home heating oil, No. 2 fuel oil and motor diesel fuel are chemically similar middle distillate fuels. Dye has been added to most taxed fuels in Canada and the United States since at least 1996 and 1993, respectively. Dye is often composed of amines: nitrogen-based organic compounds that rapidly decompose when environmentally exposed. Generally, dye is not visible after one year of exposure [8].

Geochemical approaches to fingerprinting petroleum releases include comparing concentrations of resistant hydrocarbons against rapidly-weathered hydrocarbons. The more resilient hydrocarbons include iso-alkanes, in particular, isoprenoids, cyclo-alkanes and some alkylated aromatics or terpanes, such as bicyclic sesquiterpanes [9]-[19]. Easily-weathered hydrocarbons include $n$-alkanes, some aromatics and olefins. The position and quantities of these hydrocarbons define the chromatographic signature or chemical "fingerprint" unique to crude oils and derived products. Additionally, isotopic analyses may distinguish different petroleum types and release 
modes if significant hydrocarbon weathering has not occurred. Isotopic data may also be employed to assess chlorinated solvent releases [20] [21]; such data are used to identify release modes and distinguish multiple releases.

\subsection{Investigating Gasoline Releases: Fingerprinting and Age Dating}

A powerful tool for assessing modes of gasoline discharges is the PIANO analysis. PIANO is an acronym for $n$-paraffins, iso-paraffins, aromatics, naphthenes and olefins. PIANO compounds are the predominant hydrocarbon classes in gasoline and based on certain ratios, one can often identify: (1) the gasoline's weathering; (2) how it was manufactured and its octane rating, and (3) whether it complies with regulatory standards [1]. The three factors are often central to fingerprinting or dating fugitive gasoline. The PIANO analysis is performed by combined gas chromatography/mass spectrometry (GC/MS).

If a gasoline release is historic, analyzing LNAPL for organo-metallic additives should be considered [22][24]. Former additives include: tetraethyl lead (TEL), tetramethyl lead (TML) and methylcyclopentadienyl manganese tricarbonyl (MMT). Although TEL and TML were banned as automotive additives in the United States in 1996 [23] [25] [26], their usage was generally discontinued by the late-1980s in eastern states. Organolead usage was banned in Canada in 1990 and in 2000 in most of Western Europe. The presence or absence of these compounds assist in dating gasoline releases.

\section{Discussion}

Normal alkanes (n-alkanes or n-paraffins), iso-alkanes (iso-paraffins), aromatics, naphthenes (cyclo-alkanes), olefins and oxygenates are important when dealing with light or middle-distillates; however, diesel fuel, heating oil and kerosene may be olefin- and oxygenate-free. Some hydrocarbons, such as $n$-alkanes, decompose readily under both aerobic and anaerobic conditions but at different rates, whereas others, such as iso-alkanes, tend to be more resistant; ratios of resistant to non-resistant hydrocarbons can be an index for weathering [9] [16].

Certain hydrocarbons that resist weathering are termed "biomarkers" [27] [28]. Biomarkers help fingerprinting because they consist of complex organic compounds that are found in living organisms and show modest or no structural change compared to parent molecules from which they are derived [29]; they can be highly resistant to weathering. For example, bicyclic-sesquiterpane signatures can identify the provenance of diesel fuels [30] such as an Arabian versus an Alaskan crude. A consistent or inconsistent pattern of biomarkers in samples throughout a site can also help distinguish chronic from catastrophic releases. Catastrophic releases have to be considered likely when samples from a release display similar biomarker signatures over a highly dispersed area. The rationale is that crude-oil supplies vary temporally. Therefore, biomarker signatures in the spilled product will also vary temporally. If a release occurred over months to years, biomarker signatures most likely will differ in the plume. With a release over hours or days, discharged petroleum may only represent one crude-oil reservoir, refinery or distributor and the signature may be homogenous when compared with the source product, if available.

Biomarkers used for fingerprinting include pentacyclic triterpanes, such as hopanes, regular and rearranged steranes, and mono- and tri-aromatic steranes; however, middle distillates, such as diesel fuel, home heating oil, jet fuel or kerosene, contain little residual-range hydrocarbons. Therefore, researchers must understand which type of petroleum product is being investigated and which biomarkers are appropriate for fingerprinting that type. We have had success with bicyclic sesquiterpanes for distinguishing short and long-term diesel or heating oil releases.

\section{Identifying Petroleum Products}

In the United States, over 300 million gallons of gasoline are produced daily. The quantity, per capita, is not much different in Canada, Western Europe or Japan [1]. Lesser amounts of motor diesel fuel are produced, but that quantity is increasing. Large quantities of heating oil are produced in northern and southern countries; however, in warmer countries like Brazil or Indonesia, heating oil is almost unheard of.

To identify the petroleum product in a release, LNAPL samples are often required. Unless saturated conditions exist, soil samples are less helpful because of adsorption. Many petroleum compounds of forensic interest have quite low aqueous solubilities. For example, iso-octane, the compound that the octane rating is based on, 
only has solubility in water of 2 micrograms per liter at $25^{\circ} \mathrm{C}$. Hence, iso-octane might not be detected in water samples when a compound such as benzene is present and "masks" it presence because it is greater than 900 times more soluble at the same temperature [31]. This lack-of-detection issue is exasperated when the laboratory sets its method detection limits higher than the concentration of some compounds in an effort to avert causing damage to the analytical instrument. Reanalyzing a dilute form of the sample aliquot may also prevent lower soluble compounds from being detected.

\subsection{Gasoline}

Automotive gasoline is a mixture of a natural volatile hydrocarbon fraction known as naphtha supplemented with refined hydrocarbon stocks rich in $\mathrm{C}_{5}$ - to $\mathrm{C}_{7}$-olefins $\left(\mathrm{C}_{\mathrm{n}} \mathrm{H}_{2 \mathrm{n}}\right)$, low-molecular-weight mono-aromatic hydrocarbons $\left(\mathrm{C}_{\mathrm{n}} \mathrm{H}_{2 \mathrm{n}-6}\right)$ : benzene, toluene, ethylbenzene and $o, m, p$-xylenes (collectively "BTEX”) and refinery-synthesized alkylate containing mainly the iso-alkane $\left(\mathrm{C}_{n} \mathrm{H}_{2 n+2}\right)$ 2,2,4-trimethylpentane (iso-octane). Gasoline also contains quantities of cyclo-alkanes (naphthenes) $\left(\mathrm{C}_{n} \mathrm{H}_{2 n+2}\right)$ and lesser quantities of $n$-alkanes $\left(\right.$ also $\left.\mathrm{C}_{n} \mathrm{H}_{2 n+2}\right)$. Until 1996 in the United States, 1990 in Canada and 2000 in most of Western Europe, the additives: TML, TEL and lead scavengers: ethylene dibromide (EDB or 1,2-dibromoethane) and ethylene dichloride (EDC or 1,2-dichloroethane) were often in gasoline. From about 1980, during the time that the lead additives were phased out, oxygenates, such as tert-amyl methyl ether (TAME), ethanol, diisopropyl ether (DIPE) and tert-butyl alcohol (TBA) were often substituted in amounts of less than $10 \%$ by volume. TBA was introduced as a gasoline additive in 1969, MTBE was introduced in the early- to mid-1970s, TAME was introduced in the late 1980s and ethanol has been available throughout the $20^{\text {th }}$ century. Contrarily, methyl tert-butyl ether (MTBE), another common oxygenate, was ramped up to concentrations that sometimes exceeded 15\% before MTBE usage was generally phased out in parts of the USA in the early 2000s. During the 2000s to early-2010s, ethanol was often present in US gasoline at concentrations that exceeded $10 \%$ and may have replaced ethers as the predominant oxygenate.

Gasoline can typically be identified with a gas chromatograph equipped with a flame-ionization detector (GC/FID) within the range of about $\mathrm{C}_{4}$ to $\mathrm{C}_{12}$ [32] and readily distinguished from the other products by its additives, as well as by the predominance of previously discussed iso-octanes, olefins and oxygenates.

\subsection{Avgas}

Aviation gasoline, or “avgas”, is largely alkylate and toluene with minor amounts of xylene and trimethylbenzene. Avgas was exempted from the lead ban in most countries and it normally can be distinguished from automotive gasoline by organo-lead additives; avgas contains EDB, but not EDC [23] [33]. Because of its high freezing point, $p$-xylene is often removed from avgas, which is a means of differentiating avgas from other gasolines. An important feature of avgas is its high octane rating, which is estimated through the ratio of iso-octane to methyl-cyclo-hexane [8] and other techniques discussed in [1].

\subsection{Other Middle-Distillate Fuels or Solvents}

Mineral spirits and Stoddard solvents are petroleum products in the range of $C_{7}$ to $C_{12}$, and $C_{8}$ to $C_{14}$, respectively. They are characterized by enrichment in $n$-alkanes, iso-alkanes, and naphthenes and depletion in aromatics [8]. Kerosene is a crude-oil distillate ranging from about $\mathrm{C}_{6}$ to $\mathrm{C}_{16}$, with a boiling-point range of about $125^{\circ} \mathrm{C}$ to $300^{\circ} \mathrm{C}$. Originally used for household heating and lighting, its main use now is as jet fuel. Jet A is the fuel used with commercial airliners, whereas JP-5 is the equivalent fuel for military aircraft, but use was discontinued in the late 1990s. JP-4 is a fuel used prior to 1998 for fighter planes and a mixture of kerosene and lowboiling-point naphtha. JP-8 is a kerosene-type fuel with characteristics similar to JP-5, but a wider range of $n$ alkanes, different additives and minor physical differences [34].

Kerosene is fairly easy to distinguish on a GC/FID chromatogram from motor diesel fuel or heating oil; hydrocarbons are normally within a range of $\mathrm{C}_{6}$ to $\mathrm{C}_{16}$ and the most elevated $n$-alkane peak is commonly around $\mathrm{C}_{12}$; however, differentiating jet fuel, kerosene and Arctic diesel (or \#1 diesel) is challenging because of similarities.

\section{4. \#1 Diesel Oil}

Diesel \#1 is an automotive fuel with boiling characteristics of $\sim 160^{\circ} \mathrm{C}$ to $280^{\circ} \mathrm{C}$ and mainly used in colder cli- 
mates where temperature causes viscosity problems. Its hydrocarbon range is normally $\mathrm{C}_{6}$ to $\mathrm{C}_{18}$ and somewhat lighter than normal diesel fuel (“\#2 diesel”). Diesel \#1 is differentiated from kerosene by iso-alkanes: pristane

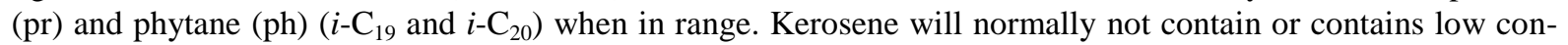
centrations of $i-\mathrm{C}_{19}$ and $i-\mathrm{C}_{20}$. Primary aromatic hydrocarbons in kerosene and diesel No. 1 are naphthalene (and methylated homologues) and methylated benzenes [35].

\section{5. \#2 Diesel Oil}

This common diesel grade is also known as a mid-distillate or motor diesel fuel and has a hydrocarbon range from $\sim \mathrm{C}_{8}$ to $\mathrm{C}_{25}$. Hydrocarbon distribution displays $n$-alkanes in the highest abundance, followed by iso-alkanes and naphthenes and a boiling point range from about $160^{\circ} \mathrm{C}$ to $400^{\circ} \mathrm{C}$. Polyaromatic hydrocarbons (PAHs) are more abundant than benzene or its $\mathrm{C}_{3}$ - to $\mathrm{C}_{4}$-alkylated homologues. Naphthalene and its $\mathrm{C}_{1}$ - to $\mathrm{C}_{4}$-methylated homologues are the most abundant PAHs. Three-ringed phenanthrene and fluorene are also prolific, as well as sulfur-containing dibenzothiophenes. In a chromatogram, the bulk of \#2 diesel fuel hydrocarbon peaks are shifted to the "right" (higher carbon ranges) relative to the positions of peaks in chromatograms of \#1 diesel oil. Further, \#2 diesel oil chromatogram patterns exhibit a Gaussian (“even”) distribution of $n$-alkane peaks which also helps to distinguish this fuel type from \#1 diesel.

\subsection{Heating Oils \#4, \#5 and \#6}

Heating oils \#4, \#5 and \#6 have higher-boiling-point distillation fractions than crude oil. With carbon ranges $>\mathrm{C}_{25}$, boiling points can exceed $600^{\circ} \mathrm{C}$. Heating oil \#6 (“Bunker C”) typically exhibits a carbon range of $\mathrm{C}_{20}$ to $\mathrm{C}_{35}+$, but because of high viscosity, it is often diluted to $\mathrm{C}_{8}$ to $\mathrm{C}_{35}+$ with mid-distillate in the range of \#2 diesel for use in cold climates. Bunker A, B, and C are essentially \#2, \#4/\#5, and \#6 fuel oil, respectively. No. 5 fuel oil is also called Navy Special Fuel Oil or "navy special”; whereas \#5/\#6 are also known as heavy fuel oil or furnace fuel oil and their viscosity requires pre-use heating. The range of PAHs in \#6 heating oil extends from naphthalene to the four-ringed fluoranthene, chrysene, and pyrene. Sulfur-containing dibenzo- and naphthothiophenes, as well as porphyrins and five-ringed pyrogenic PAHs [e.g., benzo(e)pyrene and benzo(b)fluoranthene] may be present.

\subsection{Lubricating Oils and Hydraulic Fluids/Insulating Oils}

Generally, these petroleum grades often share similar compositions and are composed primarily of iso- and cyclo-alkanes [36] [37]. Care must be exercised to avoid confusion when using chromatograms to distinguish these oils and synthetic products because lubricating oils and hydraulic fluids often have a large unresolved complex mixture (UCM) on GC/FID chromatograms. In both oils, PAHs are often absent when in an unused state, but benzene and PAHs are apparent in used oil because of incorporation from engine-fluid circulation. Normal alkanes were not commonly detected in lubricating oils prior to the late-1990s because the oil was de-waxed, but recently they are present from about $\mathrm{C}_{22}$ to $\mathrm{C}_{30}+$ and superimposed on the UCM [37].

\subsection{Creosote or Coal Tar Oil}

Creosotes and coal tars contain hydrocarbons with a boiling-point range from $\sim 160^{\circ} \mathrm{C}$ to $>500^{\circ} \mathrm{C}$ in many common coal-derived fluids. These products are largely composed of PAHs and polar compounds such as phenols and nitrogen-containing aromatic hydrocarbons. The alkanes, whether normal- or iso-, only occur in trace concentrations. The dominant compounds in order of most to least abundant are indene, naphthalene, phenanthrene, fluoranthene, pyrene, and anthracene. Pyrogenic PAHs are also prevalent in creosote. In contrast to petroleum-derived mid-range distillates, methylated PAHs are less dominant than the parent PAH and consequently have a completely different family distribution than found in petroleum products. Coal tar and its derivatives can normally be identified by its distribution of alkyl PAHs [2].

\section{Release-Mode Analysis}

Release modes can be determined once the LNAPL type is identified. The first step is to ensure that discharged petroleum is one product because co-mingling of products may render a release-mode determination irrelevant. 
There are resistant hydrocarbons that aid assessment of middle-distillates. For example, the branch-chained structure of iso-alkanes often inhibits microbial degradation [38]. Isoprenoid [pr, ph, norpristane (npr) and farnesane (fin)] concentrations can be compared as ratios (pr/ph, pr/npr, and pr/fn) to assess if they vary and evaluate the probability of chronic or catastrophic releases [39].

Anaerobic biodegradation is often the mode by which pristane and other isoprenoids commonly weather particularly when nitrate-reducing conditions are present [40] [41]. Hence, measuring the dissolved oxygen content or oxidation-reduction potential measurements of groundwater (and if possible soils) is required to determine whether anaerobic conditions prevail. In cases where two products exhibit similar or identical $n$-alkane or isoprenoid distributions, biomarker distributions may differ. Thus, rigorous comparison of biomarker ratios contributes to discriminating similar products [42] and release modes. In lighter products, like gasoline, less viable biomarkers exist; however, diamondoids $\left(\mathrm{C}_{4 \mathrm{n}+6} \mathrm{H}_{4 \mathrm{n}+12}\right)(\mathrm{m} / \mathrm{z}$ 187), such as adamantanes and diamantanes, are useful for fingerprinting gasoline [43].

\section{Case Studies}

Case study No. 1: In 2008, approximately $100 \mathrm{k}$ liters of gasoline were discovered on groundwater between the properties of a fairly new automotive-supply store and a concrete-and-gravel facility located in an agricultural setting in Canada. Based on the presence of low-boiling-point hydrocarbons in the LNAPL, it was presumed that the gasoline was fresh and the release recent; however, the gasoline exhibited a dye and contained TEL, which had been banned in Canada since 1990.

Monitoring wells were installed and the LNAPL distribution assessed by collecting samples from wells (Figure 1) exhibiting the greatest thicknesses and analyzing them for compound-specific stable-carbon $\left(\delta^{13} \mathrm{C}\right)$ ratios. The results revealed that $\delta^{13} \mathrm{C}$ values ranged from -29.4 per mil (\%o) to $-27 \%$, in BTEX (Table 1) indicating that the gasoline was fresh and a likely result of a catastrophic discharge. The error range for $\delta^{13} \mathrm{C}$ values

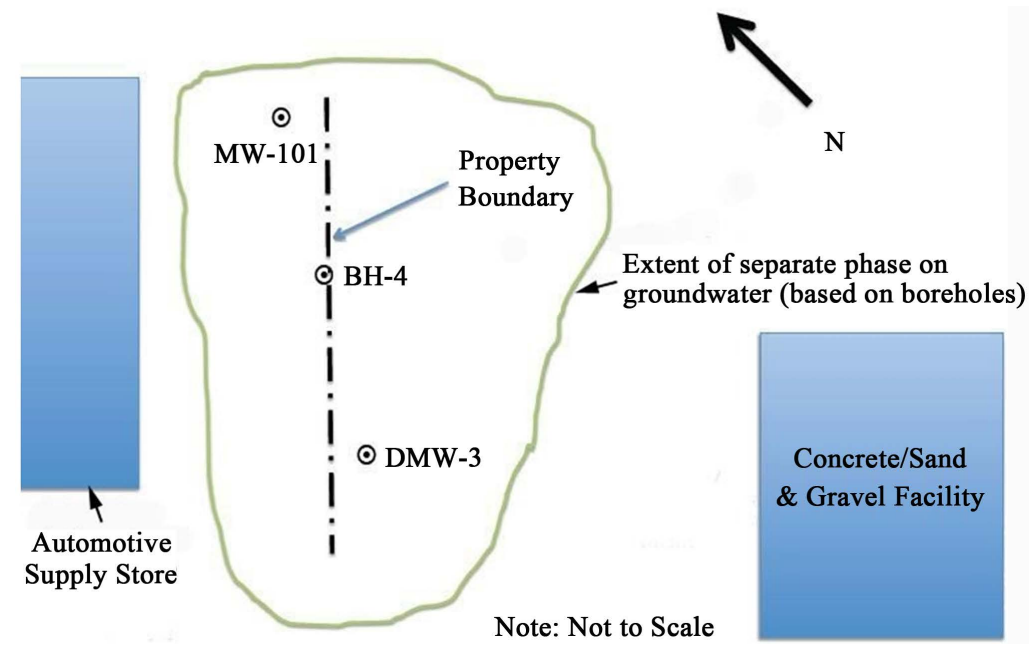

Figure 1. Sketch depicting monitoring well location and the extent of separate-phase gasoline on the water table for case study No. 1. Note: Not to scale and for illustrative purposes. Source: Triassic Technology, Inc.

Table 1. Stable carbon isotope ratios for benzene, toluene, ethylbenzene, $m, p$-xylenes and $o$-xylene in separate-phase gasoline samples from case study No. 1.

\begin{tabular}{cccccc}
\hline \multirow{2}{*}{ Well } & \multicolumn{3}{c}{ Average $\delta^{13} \mathrm{C}(\%)$} & $m, p$-Xylenes & o-Xylene \\
\cline { 2 - 5 } & Benzene & Toluene & Ethylbenzene & -28.4 & Not analyzed \\
BH-4 MW-C & -28.9 & -28.4 & -28.6 & -28.8 & -28.6 \\
DMW-3-C & -27.0 & -29.4 & -28.6 & -28.4 & Not analyzed \\
MW-101 & -29.1 & -29.4 & -29.1 &
\end{tabular}

Note: All $\delta^{13} \mathrm{C}$ values in per mil (\%). 
are commonly in the range of 5\% [44]. Accordingly, the $\delta^{13} \mathrm{C}$ values obtained for this case appear to be quite similar. Essentially, $\delta^{13} \mathrm{C}$ values increase as weathering proceeds and results of about $-30 \%$ suggested that the LNAPL was relatively fresh [20]. Because the gasoline exhibited a dye and contained TEL, it was hypothesized that it was agricultural gasoline and that by 2008 it had no longer retained value and was thus dumped. Unfortunately, this case was never resolved.

Case study No. 2: An environmental study was conducted in response to a gasoline release in an urban area. Monitoring wells were installed and, at some distance away, diesel fuel LNAPL was encountered adjacent to a dry-cleaning store located hydraulically downgradient from the gasoline release source (a service station); Figure 2. The facility operated a 2000-gallon aboveground tank for diesel-fuel storage. Seven samples of dieselfuel LNAPL were collected from temporary wells and analyzed for bicyclic sesquiterpanes. The results indicated that all seven samples exhibited similar chemical signatures. Further inquiry later indicated that the drycleaning facility suffered a catastrophic unreported overfill of $\sim 500$ gallons of diesel fuel months earlier. With these data and findings, the case was subsequently resolved.

Case study No. 3: An environmental study was conducted in response to a release of heating oil from a UST located within an urban setting. The UST was situated in front of a brownstone apartment building and numerous other off-site USTs were located nearby. Eleven soil samples and one LNAPL sample were collected through boreholes and analyzed for bicyclic sesquiterpanes (Figure 3). The samples were also analyzed with a GC/FID to assess the distribution of $n$-alkanes and assess the fuel's weathering characteristics. The results indicated that both weathered and fresh heating oils were present, whereas the sesquiterpane signatures were different among samples. Further inquiry revealed that $>20$ leaking USTs were present within the city block and that each had probably suffered long-term chronic leakages. While the chromatograms from LNAPL samples collected during this study were not published to maintain site ambiguity, Figure 4 was included from another site to demonstrate how chromatograms of LNAPL samples that were collected from the same location and depth only months apart can be used to distinguish between petroleum types and degree of weathering.

The samples represented in Figure 4(a) and Figure 4(b) were collected from the same location and depth only months apart at a location where a known transformer oil discharge occurred. The sample shown in (a) was identified as transformer oil based on the general characteristics of the chromatogram and positions of individual peaks. Note that the central portion of this chromatogram corresponds to a retention time of approximately 30

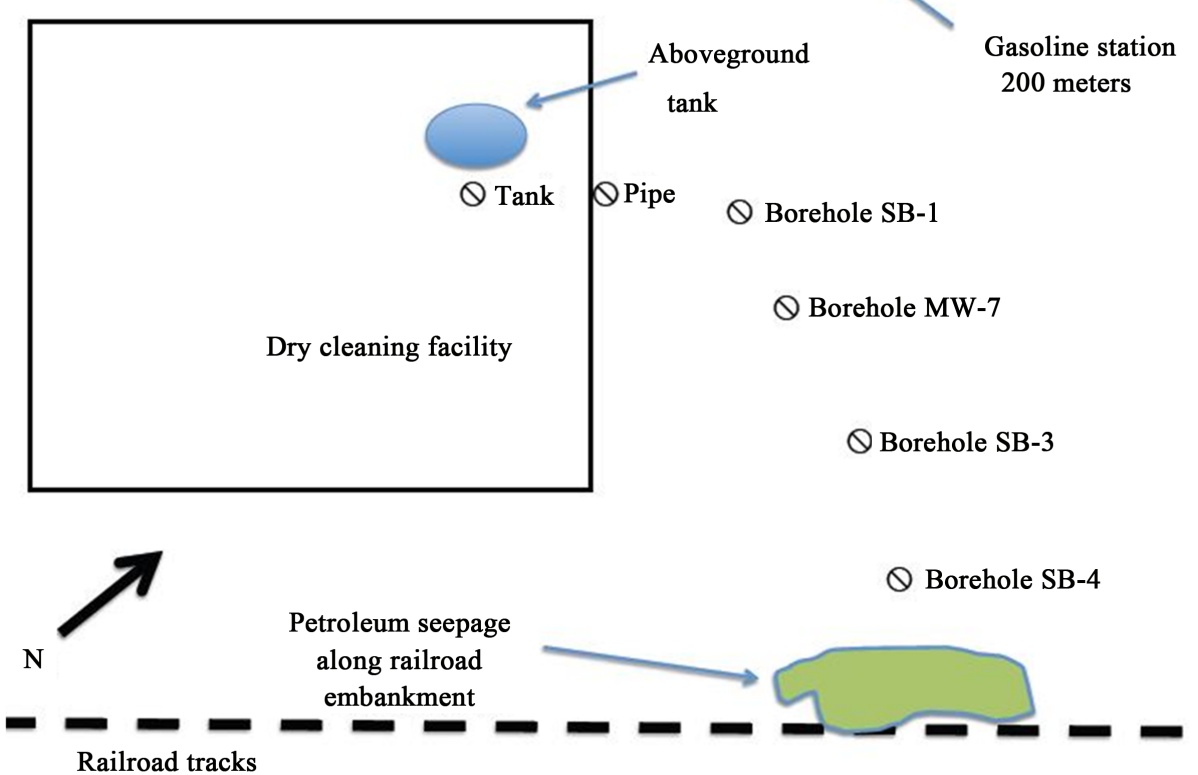

Not to scale

Figure 2. Sketch depicting the locations of the soil samples and the aboveground storage tank for case study No. 2. (Note: Not to scale and for illustrative purposes. Source: Triassic Technology, Inc). 


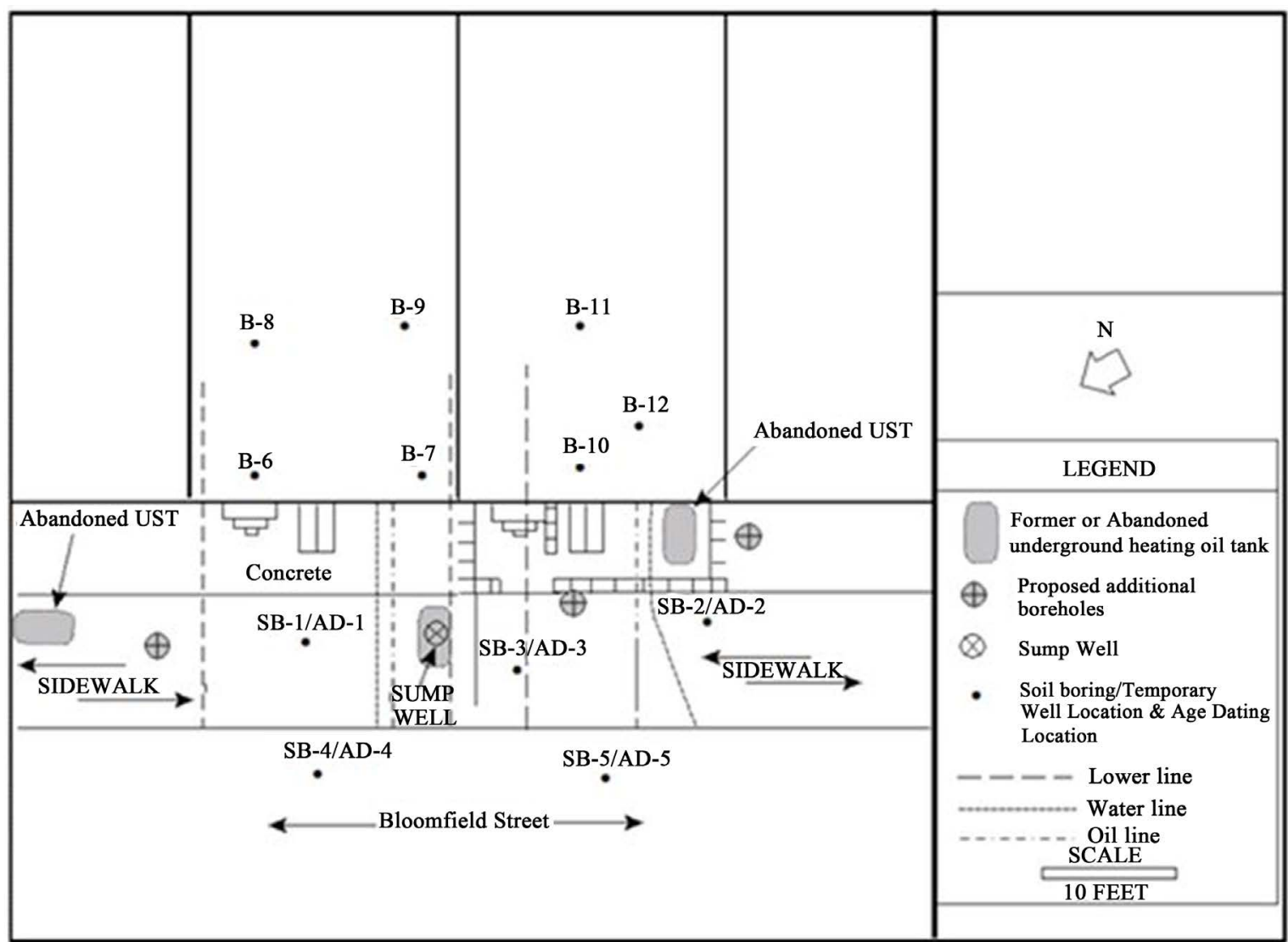

Figure 3. Locations of exploratory boreholes and underground storage tanks for case study No. 3. Source: Triassic Technology, Inc.

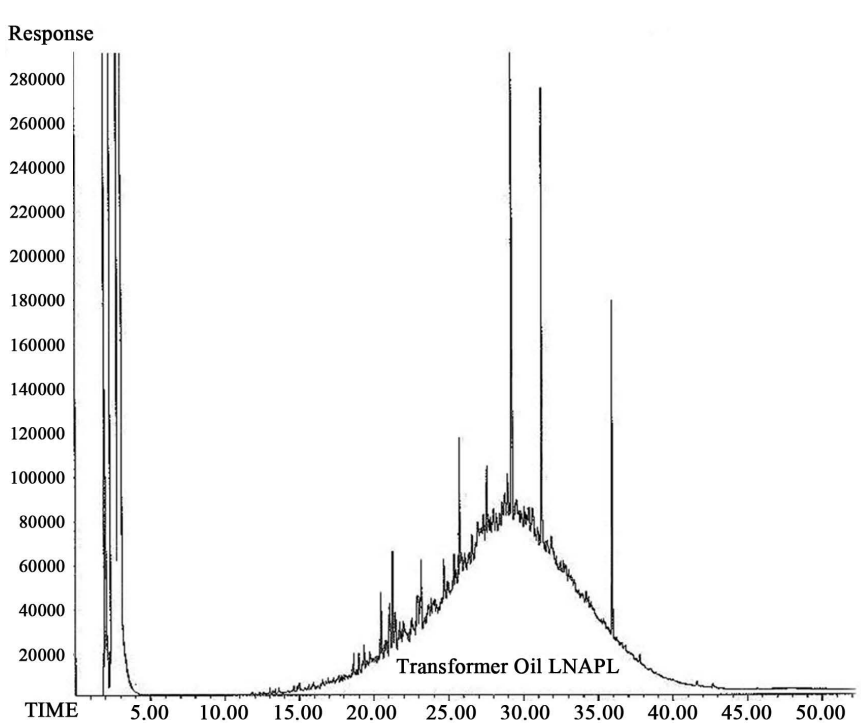

(a)

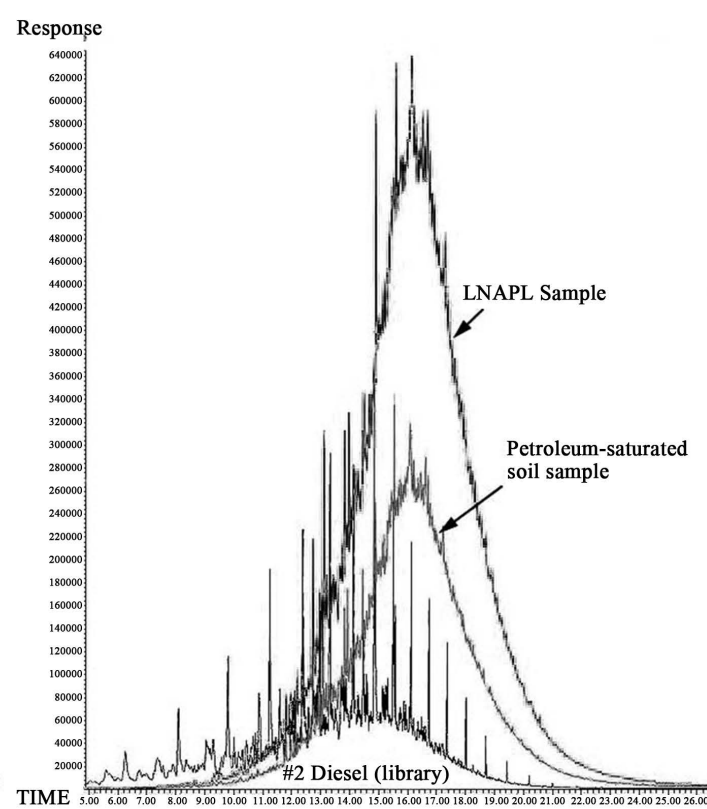

(b)

Figure 4. Example of how chromatograms can be used to distinguish between petroleum types. Source: Peak Environmental, LLC. 
minutes compared to 16 - 17 minutes for the central portion of the chromatograms associated with diesel (\#2 heating oil) in (b). This is because the constituents of transformer oil are generally composed of longer "heavier” carbon chains than those found in diesel oil. The individual peaks with retention times that fall between 20 and 23 minutes in (a) suggest that some heating oil was also present in the sample. (b) The chromatograms of two samples (LNAPL and petroleum-saturated soil) match fairly well with the chromatogram of a known laboratory standard of "fresh" (unweathered) \#2 diesel oil. A separate discharge of heating oil occurred hydraulically upgradient of the transformer area and it migrated and eventually co-mingled with the transformer oil. Possible biodegradation of the heating oil had occurred based on the loss of distinguishable peaks on the leading edge of the chromatograms. Note that the overall spectra have shifted to the right compared to the standard-this also indicates that the petroleum in the samples had weathered. Source: Peak Environmental, LLC.

\section{Conclusion}

Hydrocarbon signatures will vary spatially across a separate-phase plume following chronic releases, but are generally uniform as a result of catastrophic discharges. Thus, certain environmentally-resistant hydrocarbons, such as the biomarkers, present in these petroleum products, as well as compound-specific, stable-isotope-ratio values, are useful tools for distinguishing between chronic and catastrophic releases. With catastrophic releases, the signatures of resistant hydrocarbons (biomarkers) tend to be uniform. The cause of the uniform signatures is that these refined petroleum products will normally be derived from the same crude-oil reservoir over short periods (i.e., catastrophic releases). For chronic releases, the chemical signatures will vary throughout the plume because the source, whether it is the crude-oil reservoir, the refinery, jobber or distributor, can be quite different over extended periods of time. Care should be exercised to ensure that an appropriate analytical scheme is selected to properly characterize the type(s) of the petroleum released and the chemical nature across the entire plume. Therefore, it will be necessary to identify which petroleum product was released via known records or fingerprinting and in turn its typical physical and chemical characteristics so that an appropriate forensic framework can be developed to distinguish between catastrophic and chronic releases.

\section{References}

[1] Oudijk, G. (2013) Forensic Characterization of Gasoline Releases Impacting the Environment. Proceedings of the Soil Forensics Conference of the European Forensics Society, Den Haag, September 2012.

[2] Stout, S.A., Uhler, A.D., McCarthy, K.J. and Emsbo-Mattingly, S. (2002) Chemical Fingerprinting of Hydrocarbons. In: Murphy, B.L. and Morrison, R.D., Eds., Introduction to Environmental Forensics, Academic Press, San Diego, 137-260.

[3] Hoag, G.E. and Marley, M.C. (1986) Gasoline Residual Saturation in Saturated Uniform Aquifer Materials. American Society of Civil Engineers Environmental Engineering Division, 112, 586-604. http://dx.doi.org/10.1061/(ASCE)0733-9372(1986)112:3(586)

[4] Lyman, W.J., Reidy, P.J. and Levy, B. (1992) Mobility and Degradation of Organic Contaminants in Subsurface Environments. CRC Press, Boca Raton.

[5] Balouet, J.-C., Smith, K.T., Vroblesky, D. and Oudijk, G. (2009) Use of Dendrochrology and Dendrochemistry in Environmental Forensics: Does It Meet the Daubert Criteria? Environmental Forensics, 10, 268-276. http://dx.doi.org/10.1080/15275920903347545

[6] Balouet, J.-C., Oudijk, G., Smith, K.T., Petrisor, I., Grudd, H. and Stocklassa, B. (2007) Dendroecology and Environmental Forensics: From Fundamentals to Case Studies. Environmental Forensics, 8, 1-17. http://dx.doi.org/10.1080/15275920601180487

[7] Balouet, J.C. and Oudijk, G. (2006) The Use of Dendroecological Methods to Estimate the Time Frame of Environmental Releases. Environmental Claims Journal, 18, 1-18.

[8] Kaplan, I.R., Galperin, Y., Lu, S.-T. and Lee, R.-P. (1997) Forensic Environmental Geochemistry: Differentiation of Fuel Types, Their Sources and Release Time. Organic Geochemistry, 27, 289-317. http://dx.doi.org/10.1016/S0146-6380(97)87941-7

[9] Christensen, L.B. and Larsen, T.H. (1993) Method for Determining the Age of Diesel Spills in the Soil. Ground Water Monitoring and Remediation, 13, 142-149. http://dx.doi.org/10.1111/j.1745-6592.1993.tb00458.x

[10] Wade, M.J. (2001) Age-Dating Diesel Spills: Using the European Empirical Time-Based Model in the USA. Environmental Forensics, 2, 347-358. http://dx.doi.org/10.1006/enfo.2001.0069 
[11] Hurst, R.W. and Schmidt, G.W. (2005) Age Significance of nC17/pr Ratios in Forensic Investigations of Refined Product and Crude Oil Releases. Environmental Geosciences, 12, 177-192. http://dx.doi.org/10.1306/eg.04260404004

[12] Galperin, Y. and Camp, H. (2002) Petroleum Product Identification in Environmental Samples: Distribution Patterns in Fuel-Specific Homologous Series. Soil and Sediment Contamination, April/May Issue, 27-29.

[13] Hurst, R.W. and Schmidt, G.W. (2007) Age Significance of nC17/pr Ratios in Forensic Investigations of Refined Product and Crude Oil Releases: Reply. Environmental Geosciences, 14, 111-112. http://dx.doi.org/10.1306/eg.013007R07002

[14] Oudijk, G. (2007) Age Significance of n-C17/pr Ratios in Forensic Investigations of Refined Product and Crude Oil Releases: Discussion. Environmental Geosciences, 14, 110-112. http://dx.doi.org/10.1306/eg.013007D06009

[15] Kaplan, I.R. and Galperin, Y. (2008) Zero-Order Kinetics Model for the Christensen-Larsen Method for Fugitive Fuel Age Estimates. Ground Water Monitoring and Remediation, 28, 94-97. http://dx.doi.org/10.1111/j.1745-6592.2008.00196.x

[16] Oudijk, G. (2009) Age Dating Heating-Oil Releases, Part 1: Heating-Oil Composition and Subsurface Weathering. Environmental Forensics, 10, 107-119. http://dx.doi.org/10.1080/15275920902873384

[17] Oudijk, G. (2009) Age Dating Heating-Oil Releases, Part 2: Assessing Weathering and Release Time Frames through Chemistry, Geology and Site History. Environmental Forensics, 10, 120-131. http://dx.doi.org/10.1080/15275920902945885

[18] Oudijk, G. and Wade, M.J. (2011) On Age-Dating Distillate Fuels: A Commentary on the Methods of Hurst and Schmidt (2005) and Galperin and Kaplan (2008). Environmental Forensics, 12, 1-2. http://dx.doi.org/10.1080/15275922.2011.547434

[19] Oudijk, G. (2012) Uso dos Biomarcadores para Identificar a Origem da Contaminação pot Petróleo. Revista Água, 5, 32-33.

[20] Philp, R.P. (2002) Application of Stable Isotopes and Radioisotopes in Environmental Forensics. In: Murphy, B. and Morrison, R.D., Eds., Introduction to Environmental Forensics, Chap. 5, Academic Press, San Diego, 395-455.

[21] Philp, R.P. (2007) The Emergence of Stable Isotopes in Environmental and Forensic Geochemistry Studies: A Review. Environmental Chemistry Letters, 5, 57-66. http://dx.doi.org/10.1007/s10311-006-0081-y

[22] Oudijk, G. (2012) The History of Leaded Petrol in North America and Europe. Environmental Forensics. In: Morrison, R.D. and O'Sullivan, G., Eds., Proceedings of the 2011 INEF Conference, RSC Publishing, Cambridge, UK, 49-63. http://dx.doi.org/10.1039/9781849734967-00049

[23] Oudijk, G. (2010) The Rise and Fall of Organometallic Additives in Automotive Gasoline. Environmental Forensics, 1, 17-49. http://dx.doi.org/10.1080/15275920903346794

[24] Oudijk, G. (2005) Fingerprinting and Age Dating of Gasoline Releases-A Case Study. Environmental Forensics, 6, 2-10. http://dx.doi.org/10.1080/15275920590913994

[25] Wade, M.J. (2014) Failures in the Historical Age Dating of Separate Phase Product Leaded Gasoline Releases in the United States Forensic Geochemical Community. Proceedings of the International Network of Environmental Forensics conference, State College, 10-12 June 2013, 37-66. http://dx.doi.org/10.1039/9781782628347-00037

[26] Oudijk, G. (2007) The Use of Alkyl Leads in Gasoline Age-Dating Investigations: New Insights, Common Investigative Techniques, Limitations and Recommended Practices. Environmental Claims Journal, 19, 68-87. http://dx.doi.org/10.1080/10406020601158329

[27] Philp, R.P. (1985) Fossil Fuel Biomarkers. Elsevier, New York.

[28] Wang, C., Du, J., Gao, X., Duan, Y. and Sheng, Y. (2011) Chemical Characterization of Naturally Weathered Oil Residues in the Sediment from Yellow River Delta, China. Marine Pollution Bulletin, 62, 2469-2475. http://dx.doi.org/10.1016/j.marpolbul.2011.08.021

[29] Philp, R.P. and Lewis, C.A. (1987) Organic Geochemistry of Biomarkers. Annual Reviews of Earth and Planetary Science, 15, 363-395. http://dx.doi.org/10.1146/annurev.ea.15.050187.002051

[30] Stout, S.A., Uhler, A.D. and McCarthy, K. (2005) Middle Distillate Fuel Fingerprinting Using Drimane-Based Bicyclic Sequiterpanes. Environmental Forensics, 6, 241-252. http://dx.doi.org/10.1080/15275920500194407

[31] Bruce, L., Miller, T. and Hochman, B. (1991) Solubility versus Equilibrium Saturation of Gasoline Compounds: A Method to Estimate Fuel/Water Partition Coefficient Using Solubility of Koc. AGWSE/API Conference on Petroleum Hydrocarbons and Organic Chemicals in Ground Water, Houston, 571-582.

[32] Maxxam Analytical (2008) Chromatogram Interpretation Guide. Mississauga, Ontario, unpublished.

[33] Falta, R.W. (2004) The Potential for Ground Water Contamination by the Gasoline Lead Scavengers Ethylene Dibromide and 1,2-Dichloroethane. Ground Water Monitoring and Remediation, 24, 76-87. http://dx.doi.org/10.1111/j.1745-6592.2004.tb01294.x 
[34] United States Department of Defense (2003) Toxicological Assessment of Jet-Propulsion Fuel 8. Subcommittee of Jet-Propulsion Fuel 8, Committee on Toxicology, National Research Council, 230 p.

[35] Kaplan, I.R. and Galperin, Y. (1996) Patterns of Chemical Changes during Environmental Alteration of Hydrocarbon Fuels. Ground Water Monitoring and Remediation, 16, 113-124. http://dx.doi.org/10.1111/j.1745-6592.1996.tb01178.x

[36] Lu, S.-T. and Kaplan, I.R. (2008) Characterization of Motor Lubricating Oils and Their Oil-Water Partition. Environmental Forensics, 9, 295-309. http://dx.doi.org/10.1080/15275920802119441

[37] Kaplan, I.R., Rasco, J. and Lu, S.-T. (2010) Chemical Characterization of Transformer Mineral-Insulating Oils. Environmental Forensics, 11, 117-145. http://dx.doi.org/10.1080/15275920903558760

[38] Schaeffer, T.L., Cantwell, S.G., Brown, J.L., Watt, D.S. and Fall, R.R. (1979) Microbial Growth on Hydrocarbons: Terminal Branching Inhibits Biodegradation. Applied and Environmental Microbiology, 38, 742-746.

[39] Oudijk, G. (2012) Age Dating of Middle-Distillate Fuels Released to the Subsurface Environment. In: Dar, I.A., Ed., Earth Sciences, Chap. 12, InTech, Croatia, 541-583. http://dx.doi.org/10.5772/28382

[40] Hostettler, F.D., Bekins, B.A., Rostad, C.E. and Herkelrath, W.N. (2008) Response to Commentary on Observed Methanogenic Biodegradation Progressions. Environmental Forensics, 9, 121-126. http://dx.doi.org/10.1080/15275920802115738

[41] Bregnard, T.P.-A., Häner, A., Höhener, P. and Zeyer, J. (1997) Anaerobic Degradation of Pristane in Nitrate-Reducing Microcosms and Enrichment Cultures. Applied and Environmental Microbiology, 63, 2077-2081.

[42] Wang, Z.D., Fingas, M., Yang, C. and Hollebone, B. (2004) Biomarker Fingerprinting: Application and Limitation for Correlation and Source Identification of Oils and Petroleum Products. Preprint Paper-American Chemical Society, Division of Fuel Chemistry, 49, 331-334.

[43] Stout, S.A. and Douglas, G.C. (2004) Diamondoid Hydrocarbons-Application in the Chemical Fingerprinting of Natural Gas Condensate and Gasoline. Environmental Forensics, 5, 225-235. http://dx.doi.org/10.1080/15275920490886734

[44] Philp, P.R. (2011) Personal Communication. 